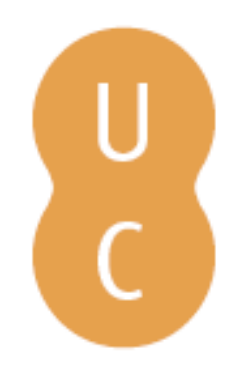

\title{
pommalina
}

\section{Calibration of the Canadian FWI system for the territory of Europe}

Autor(es): $\quad$ Alves, Daniela; Ribeiro, Luís Mário; Viegas, Domingos Xavier

Publicado por: Imprensa da Universidade de Coimbra

URL

persistente: URI:http://hdl.handle.net/10316.2/44520

DOI: $\quad$ DOl:https://doi.org/10.14195/978-989-26-16-506_3

Accessed : $\quad$ 26-Apr-2023 16:00:40

A navegação consulta e descarregamento dos títulos inseridos nas Bibliotecas Digitais UC Digitalis, UC Pombalina e UC Impactum, pressupõem a aceitação plena e sem reservas dos Termos e Condições de Uso destas Bibliotecas Digitais, disponíveis em https://digitalis.uc.pt/pt-pt/termos.

Conforme exposto nos referidos Termos e Condições de Uso, o descarregamento de títulos de acesso restrito requer uma licença válida de autorização devendo o utilizador aceder ao(s) documento(s) a partir de um endereço de IP da instituição detentora da supramencionada licença.

Ao utilizador é apenas permitido o descarregamento para uso pessoal, pelo que o emprego do(s) título(s) descarregado(s) para outro fim, designadamente comercial, carece de autorização do respetivo autor ou editor da obra.

Na medida em que todas as obras da UC Digitalis se encontram protegidas pelo Código do Direito de Autor e Direitos Conexos e demais legislação aplicável, toda a cópia, parcial ou total, deste documento, nos casos em que é legalmente admitida, deverá conter ou fazer-se acompanhar por este aviso.

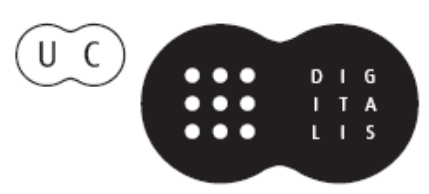




\section{ADVANCES IN}

\section{FOREST FIRE RESEARCH}

\section{8}

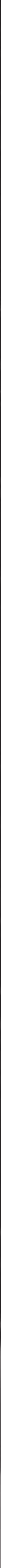




\title{
Calibration of the Canadian FWI System for the Territory of Europe
}

\author{
Daniela Alves*; Luís Mário Ribeiro; Domingos Xavier Viegas \\ Forest Fire Research Centre (CEIF), ADAI-LAETA, University of Coimbra. Coimbra 3030-289, \\ Portugal. \{danielaalves@adai.pt*\}
}

\begin{abstract}
The role played by the meteorology in the development of a forest fire is widely recognized. There are several models to assess the risk of forest fires used by the authorities to define the state of readiness of the fire-fighting resources to suppress them in their early stages. The Fire Weather Index (FWI) of the Canadian Fire Danger System, widely used in several parts of the world, is a composite index that represents fire weather conditions quite well.

An important aspect in the application of the FWI is the definition of the threshold values to determine the fire danger classes for a given region and day. One of the simplest methods to define the classes is to use percentiles based on historical data, but this method lacks information regarding wildfire history and its relation to FWI. To obtain a credible assessment of the fire danger using the FWI it is important to perform a calibration to determine the limiting values of FWI for each class. Probabilities of fire duration exceeding specified thresholds are then used to calibrate FWI leading to the definition of fire danger classes. Although the Canadian Fire Danger System proposes an indicative table of limiting values for the five original fire danger classes that are usually adopted, these limiting values are not universal and have to be determined for a given region and season.

This study that was requested by the Joint Research Centre of Europe (JRC), aims to produce a calibration for the FWI based on historical wildfire data, for the territory of Europe, providing an updated table of threshold values to have a better definition of the risk classes of each region. The spatial division of the various countries and regions covered by the daily analysis of fire risk was defined to be the level 3 of the Nomenclature of territorial units for statistics (NUTS3). The methodology to calibrate the fire danger classes based on the statistical data of daily FWI, number of fires and burned area for each NUTS3, was performed between 2006 and 2015.
\end{abstract}

Keywords: fire danger, fire meteorology, Canadian Fire Danger System, Fire Weather Index

\section{Introduction}

Forest fire danger is greatly dependent on meteorological conditions, although the fire risk depends on other factors like vegetation cover and socio-economic parameters, namely those related to fire ignition, fire prevention and fire suppression activities.

In forest fire management, the need for understanding and predicting fire ignition probability and difficulty of control is the main reason for collecting fire statistics and for the development and use of fire danger rating systems (Xanthopoulos, et al., 2014). These systems are usually translated into a general risk scale with 3 to 6 fire danger classes. There are multiple methods for estimating the fire danger classes, based on meteorological parameters, which are used around the world. Several methods were developed with the aim of being applied to a given region or country, considering the specific fire regime; others were developed considering a more general application. In some countries, several systems are used to estimate the index, leaving the decision to adopt the most appropriate level of risk in each situation to the users (Viegas, et al., 2011). 
The Fire Weather Index (FWI) of the Canadian Fire Danger System has a very broad use not only in Canada but also in other parts of the world including Europe (Stocks et al. 1989, Forestry Canada Fire Danger Group, 1992). The Fire Weather Index (FWI) component of this system was evaluated favourably, among others, by Viegas et al. (1999) in comparison with four other methods of fire danger evaluation. More information on the existing methods can be found in Viegas et al. (1994) and Reis (1998).

An important aspect in the application of the FWI is the definition of the threshold values to determine the fire danger classes for a given region and day. Although the Canadian system proposes an indicative table of limiting values for the five original fire danger classes that are usually adopted, these limiting values are not universal and have to be determined for a given region and season. One of the simplest methods to present classes is to use percentiles based on historical data, but this method lacks information regarding wildfire history and its relation to FWI. To obtain a credible assessment of the fire danger using the FWI it is important to perform a calibration to validate the limiting values of FWI for each class.

In 1999, ADAI/CEIF team proposed and applied an original calibration of the FWI index which was developed in collaboration with the Portuguese Institute of Meteorology (Viegas, et al., 2004) and was performed for each district of Portugal. A recent work (Rocha, 2014), extended this calibration to the council level using more recent data, showing that the methodology used is quite robust, and can help to identify differences between and within regions.

By solicitation of the Joint Research Centre of Europe, ADAI/CEIF performed a calibration, based on the mentioned methodology, for the European Countries that are present in the European Forest Fire Information System (EFFIS - http://effis.jrc.ec.europa.eu/).

\subsection{Canadian Fire Danger System}

The Canadian Fire Danger System characterized by its FWI, is the result of years of research applied in Canada since 1968, culminating in the presentation of the system in a document presented by Van Wagner (1987). The structure of the Canadian system succinctly presents 3 levels: the meteorological observations, the fire moisture codes and the fire behaviour indexes.

The FWI is an indicator of the fire behaviour and fire danger and is the output parameter of the system which is more directly related to the possibility of occurrence of fires and with the respective danger and represents only a part of the complex role of meteorology in forest fires. For a more detailed information on the meaning of the different components of the Canadian system, as well as for obtaining the mathematical formulas which relate the variables involved, see Van Wagner (1987).

\subsection{Objectives}

Fire Weather Index does not consider only weather parameters, excluding aspects such as socio economic factors, topography, vegetation or fuel cover. For these reasons the interpretation of FWI values can be different from region to region. FWI is used in Portugal and in other countries of Europe with differences in its assessment: different input data, different calibration system and different interpretation of results.

In this work we applied a calibration method to the territory of Europe to provide the JRC with an updated table of threshold values to better define the class of risk of each region considering, not only the meteorological conditions, but also the history of fire occurrence in terms of daily fires and burned area.

\section{Methodology - Calibration of the Canadian System}

The conceptual basis of the Canadian system uses physical parameters, like the equilibrium moisture content and its relationship with meteorological parameters. Therefore its application can be 
extended to other ecosystems beyond those for which it was initially developed. This application, however, requires that a system calibration is performed for each specific region.

The proposed calibration process is based on fire history of the region in which it will be applied, and its relation to FWI. Therefore, the first and crucial step, was to define the optimal physical or spatial unit to be used in the process. The only limitation for choosing this unit lays on the existence of input data, both related to FWI and fire records. In agreement with the JRC, the spatial unit of the various countries and regions covered by the daily analysis of fire risk was defined to be NUTS3, and the period selected for calibration was 2006 to 2015. The NUTS classification (Nomenclature of Territorial Units for Statistics) is a hierarchical system for dividing up the economic territory of the EU (http://ec.europa.eu). The current NUTS 2016 classification is valid from 1 January 2018 and lists 104 regions at NUTS 1, 281 regions at NUTS 2 and 1348 regions at NUTS 3 level (European Commission, 2018). The $3^{\text {rd }}$ level has the smallest dimension.

For the proposed calibration for a region and time, the parameters used were:

- The daily FWI values;

- The number of forest fires $(\mathrm{NbF})$

- The burned area (BA);

Assuming that there are different fire patterns across Europe, depending on the time of year, it was decided to perform the calibration process for two different seasons. The first includes the months with higher fire activity, usually late Spring and Summer. The second corresponds to the rest of the year. A preliminary analysis (Section 2.2.1) was performed to define these periods: the "Summer Season" was considered to be the period from May $15^{\text {th }}$ to September $30^{\text {th }}$ and "Winter Season" from October $1^{\text {st }}$ to May $14^{\text {th }}$.

This section describes the methodology used to calibrate the FWI. The process was the same for all NUTS3, obviously using the individual records for each region and some general considerations, identified below. This process can be repeated with other sets of data (spatial or temporal).

\subsection{General considerations}

According to the methodology proposed in Viegas et al. (2004), the concept of high or low risk has a relative character and can be different across various territories. Fire history, prevention actions and available suppression resources in each region can largely influence this classification.

The result of the calibration is translated into risk levels, usually on a five level scale. For the Summer season we considered the existence of five fire danger classes while for the Winter season we considered only three. In regions or periods of the year, such as in winter and spring, where the occurrence of fires is lower, a scale of only three levels can be sufficient (Viegas et al., 2011).

The main fire seasons were defined using the fire occurrence data which were observed in each country during the years of analysis. The proposed risk levels and the respective classes for each season are presented in Section 2.2.9 (Table ). It is considered that the days of maximum risk (very high class) should not be many, on average, to avoid distorting the meaning of this term. In the calibration methodology design it was established that this number should not exceed 3 to $5 \%$ of the total days in the considered period.

This methodology is based on the existence of a good correlation between the daily value of FWI in a given region and the corresponding value of burned area and number of fires. For most regions with strong fire activity (like the Mediterranean Countries) we have checked that this assumption is correct in the large majority of cases. When developing the work, we checked regularly the validity of this assumption for various territorial units and found that it is usually better for the relationship between FWI and the number of daily fires, but this was not always the case. 


\subsection{Calibration steps}

\subsubsection{Collecting, preparing and analyzing fire records data}

Fire records for Europe were provided by JRC. A preliminary analysis of the data to retain records where the following fields were known:
i. Burned area
ii. NUTS 3
iii. Date

In this analysis we found that some of the European NUTS3 regions do not have fire records. This is shown in Figure .

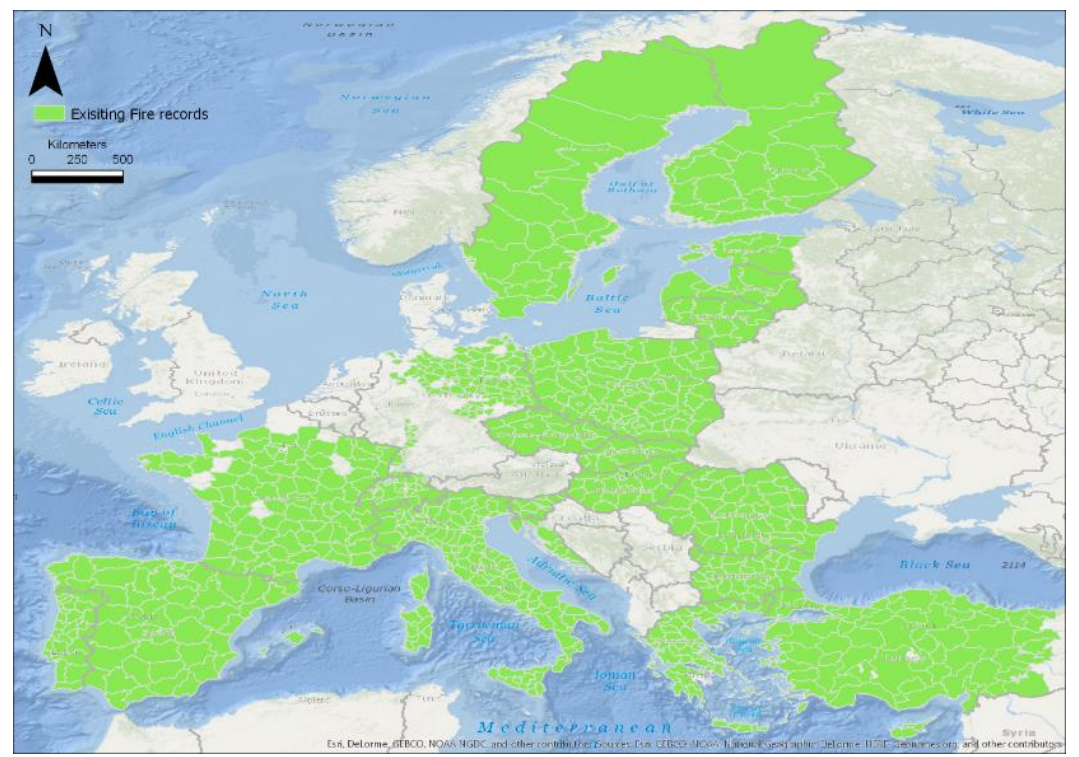

Figure 1 - Map depicting the extent of the provided fire records

In a second stage, we analyzed the number of fires per country and their respective burned area. Figure represents these results per year. This gives a simple indication of wildfires average burned area in each country. It may not be representative in some cases, as countries with very few fires can have one large fire that conditions this result.

In Figure 3 we represent the annual average burned area in relation to the respective country total area. It is clear that, in general, the Mediterranean Basin countries like Portugal (PT), Spain (ES), Italy (IT) or Greece (EL) are the most affected ones, either in number of fires or burned area. Portugal has an average of $0.83 \%$ of its area burned by wildfires each year.

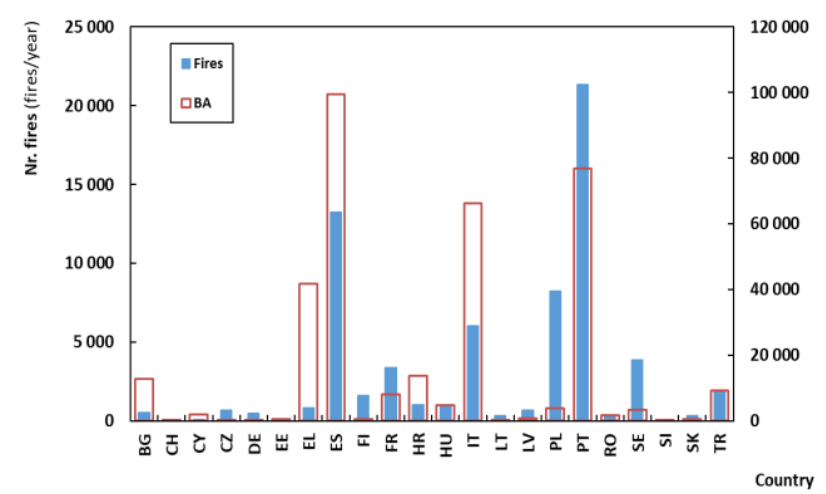

Figure 2 - Number of fires and Burned area

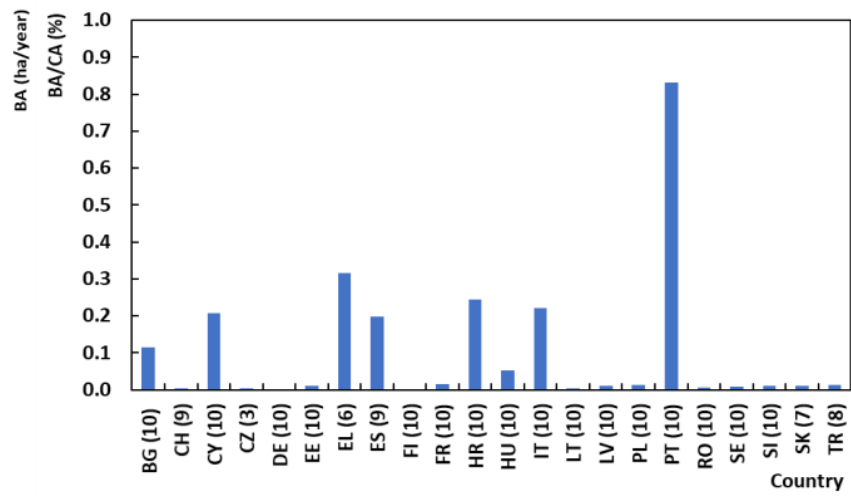

Figure 3 - Annual average of burned area/Country area (\%) 
In Figure and Figure the number of fires and burned area is shown, globally, for the two proposed seasons (Summer and Winter).

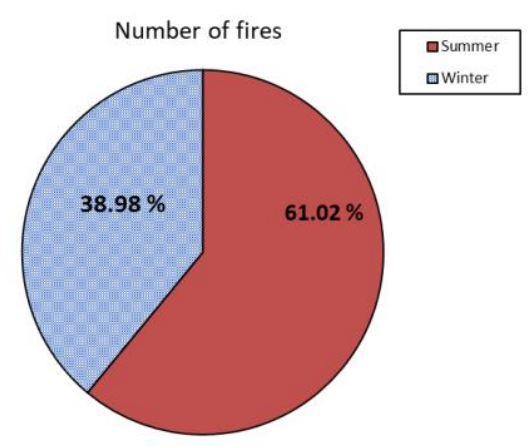

Figure 4 - Total number of fires, in percent, in Summer and Winter seasons

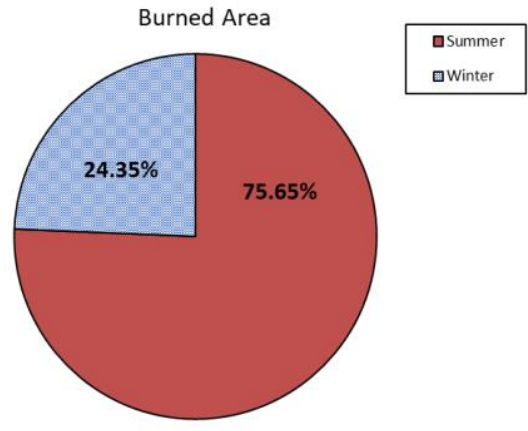

Figure 5 - Total burned area, in percent, in Summer and Winter seasons

The selected dates for the two different seasons seem to be representative, as two thirds of the number of fires and three quarters of the burned area occur in the Summer period, although this may be different for some regions.

After this preliminary analysis, we found no evidence or need to have different seasons in different NUTS3 areas. The same periods were therefore used for all the regions. Nevertheless, we recognize that in some regions where fires occur mostly in the Winter period this criterium may have to be revisited.

\subsubsection{Evaluating FWI (provided by JRC)}

Evaluation of the daily value of FWI is made by estimation of an average daily value of the relevant meteorological parameters: air temperature, relative humidity, wind velocity and precipitation. In this work FWI was provided directly by JRC in the form of an evenly spaced grid of points covering Europe. For the period of 2006-2015, the following fields were provided:

$\begin{array}{llll}\text { i. } & \text { Point ID; } & \text { v. } & \text { DMC; } \\ \text { ii. } & \text { X and Y coordinates; } & \text { vi. } & \text { DC; } \\ \text { iii. } & \text { FWI; } & \text { vii. } & \text { ISI; } \\ \text { iv. } & \text { FFMC; } & \text { viii. } & \text { BUI. }\end{array}$

For the proposed calibration process, only the FWI value was used. As the spatial unit used for the calibration process is NUTS3, FWI values were spatially interpolated and a mean value was assigned to each NUTS3 polygon. ArcMap was used for this step of the process. The interpolations were done using the Thiessen polygons method. When the process ended, each NUTS 3 polygon had the FWI values for every day of each year of the study period.

\subsubsection{Defining Study Area or Area of Interest (AoI)}

As stated before, the Area of Interest (AoI) needs to meet the requisites of having both historical fire and FWI data at the defined spatial division of NUTS 3 that were provided by JRC for the period chosen for the calibration (2006-2015). FWI was made available for all the territory. Unfortunately, the fire data was not homogeneously distributed in time and/or space. The main constrain was the absence of fire data in certain countries in some periods and the complete absence in others. Table 1 presents the countries for which fire records existed, the respective number of NUTS3, and the period for which it was available. 
Table 1 - Countries analyzed - study area

\begin{tabular}{|l|c|c|c|c|c|c|}
\hline \multirow{2}{*}{ Country } & \multicolumn{2}{c|}{ Number of NUTS3 } & \multicolumn{3}{c|}{ Fire Data period } \\
\cline { 3 - 7 } & & All country & With data & From & To & Years \\
\hline Bulgaria & BG & 28 & 28 & 2006 & 2015 & 10 \\
\hline Croatia & HR & 21 & 7 & 2006 & 2015 & 10 \\
\hline Cyprus & CY & 1 & 1 & 2006 & 2015 & 10 \\
\hline Czech Republic & CZ & 14 & 14 & 2006 & 2008 & 3 \\
\hline Estonia & EE & 59 & 5 & 2006 & 2015 & 10 \\
\hline Finland & FI & 19 & 18 & 2006 & 2015 & 10 \\
\hline France & FR & 100 & 84 & 2006 & 2015 & 10 \\
\hline Germany & DE & 402 & 101 & 2006 & 2015 & 10 \\
\hline Greece & EL & 52 & 50 & 2006 & 2011 & 6 \\
\hline Hungary & HU & 20 & 20 & 2006 & 2015 & 10 \\
\hline Italy & IT & 110 & 110 & 2006 & 2015 & 10 \\
\hline Latvia & LV & 6 & 6 & 2006 & 2015 & 10 \\
\hline Lithuania & LT & 10 & 10 & 2006 & 2015 & 10 \\
\hline Poland & PL & 72 & 66 & 2006 & 2015 & 10 \\
\hline Portugal & PT & 30 & 28 & 2006 & 2015 & 10 \\
\hline Romania & RO & 42 & 42 & 2006 & 2015 & 10 \\
\hline Slovakia & SK & 8 & 8 & 2006 & 2012 & 7 \\
\hline Slovenia & SI & 12 & 12 & 2006 & 2015 & 10 \\
\hline Spain & ES & 59 & 52 & 2006 & 2014 & 9 \\
\hline Sweden & SE & 21 & 21 & 2006 & 2015 & 10 \\
\hline Switzerland & CH & 26 & 23 & 2006 & 2014 & 9 \\
\hline Turkey & TR & 81 & 63 & 2006 & 2013 & 8 \\
\hline & & & & & & \\
\hline
\end{tabular}

Therefore, the definition of the AoI was constrained by the fire records availability, and it coincides with the areas already identified in Figure .

\subsubsection{Merging datasets}

After AoI definition, FWI and Fire records datasets were merged into one single alphanumeric dataset. Table shows an example of final merged dataset.

Table 2 - Final merged full dataset

\begin{tabular}{|c|c|c|c|c|c|c|c|c|c|c|c|}
\hline NUTS_ID & Day & NbF & BA & FWI & FFMC & DMC & DC & ISI & BUI & Num_date & Date_nuts_join \\
\hline PT111 & $31 / 07 / 2006$ & 3 & 43.1 & 21.6 & 83.3 & 80.7 & 605.2 & 5.1 & 121.1 & 38929 & 38929 PT111 \\
\hline PT112 & $31 / 07 / 2006$ & 9 & 1.1 & 21.6 & 83.3 & 80.8 & 605.2 & 5.1 & 121.1 & 38929 & $38929 P T 112$ \\
\hline
\end{tabular}

\subsubsection{Harmonization and calculation}

From this step forward, all calculations were done for each NUTS 3 and for the Summer and Winter periods in separate, which required the full dataset to be split accordingly: ${ }^{\text {st }}$ ) Split full dataset by NUTS 3 and $2^{\text {nd }}$ ) Split each NUTS 3 into Summer and Winter periods

This resulted in a set of 769 individual tables for Summer and the same number for Winter (corresponding to the sum of the NUTS 3 regions with fire records, as identified in Table 1). The process of calibration for each NUTS 3 region is described next.

\subsubsection{Reordering FWI by ascending order and add cumulative days}

At this point all it matters is the value of FWI, the number of days in the analysis and their relationship with fire records. Maintaining the correspondence between all fields the table is rearranged by ordering the FWI column in an ascending order. Afterwards, the "Date" field is replaced by a 
numerical incremental field, with the value of " 1 " being attributed to the record with the lowest value of FWI, and consecutively adding " 1 " to the following record. Table 3 schematically represents this procedure.

Table 3 - Sorting FWI Values and adding incremental days field

\begin{tabular}{|c|c|c|c|}
\hline \multicolumn{3}{|c|}{ Original } \\
\hline Date & FWI & $\begin{array}{c}\text { Number } \\
\text { of fires }\end{array}$ & $\begin{array}{c}\text { Burned } \\
\text { area (ha) }\end{array}$ \\
\hline Date_1 & FWI_3 & NbF_1 & BA_1 \\
\hline Date_2 & FWI_4 & NbF_2 & BA_2 \\
\hline Date_3 & FWI_2 & NbF_3 & BA_3 \\
\hline Date_4 & FWI_1 & NbF_4 & BA_4 \\
\hline Date_n & FWI_n & NbF_n & BA_5 \\
\hline
\end{tabular}

$\rightarrow$\begin{tabular}{c|c|c|c|}
\hline \multicolumn{4}{|c|}{ After re-ordering } \\
\hline $\begin{array}{c}\text { Incremental } \\
\text { day }\end{array}$ & FWI & $\begin{array}{c}\text { Number } \\
\text { of fires }\end{array}$ & $\begin{array}{c}\text { Burned } \\
\text { area (ha) }\end{array}$ \\
\hline $\mathrm{d} 1$ & FWI_1 & NbF_4 & BA_4 \\
\hline $\mathrm{d} 2$ & FWI_2 & NbF_3 & BA_3 \\
\hline d3 & FWI_3 & NbF_1 & BA_1 \\
\hline d4 & FWI_4 & NbF_2 & BA_2 \\
\hline dTotal & FWI_n & NbF_n & BA_n \\
\hline
\end{tabular}

\subsubsection{Adding probability field}

A new field called "Probability" was then added. This field reflects the weight that a given day (and its respective FWI) has in respect to the total number of days. The higher the FWI, the higher the "incremental day" and the higher the respective "probability" of occurrence of values of FWI lower than the specified value. The probability field is calculated by dividing the "incremental day" number, by the total number of days:

$$
\text { Probability }=\frac{\text { Incremental day }\left(d_{n}\right)}{\text { Incremental day total }\left(d_{\text {Total }}\right)}
$$

Table represents the resulting table after the addition and calculation of the probability field.

Table 4. Adding the probability field

\begin{tabular}{|c|c|c|c|c|}
$\begin{array}{c}\text { Incremental } \\
\text { day }\end{array}$ & Probability & FWI & Number of fires & Burned Area (ha) \\
\hline$d 1$ & d1/dTotal & FWI_1 & NbF_4 & BA_4 \\
\hline$d 2$ & d2/dTotal & FWI_2 & NbF_3 & BA_3 \\
\hline$d 3$ & d3/dTotal & FWI_3 & NbF_1 & BA_1 \\
\hline$d 4$ & d4/dTotal & FWI_4 & NbF_2 & BA_2 \\
\hline$d$ Total & 1 (=dTotal/dTotal) & FWI_n & NbF_n & BA_n \\
\hline
\end{tabular}

Adding the number of fires and burned area, allows a graphical representation of the cumulative probability, as the example for PT111 region, shown in Figure .
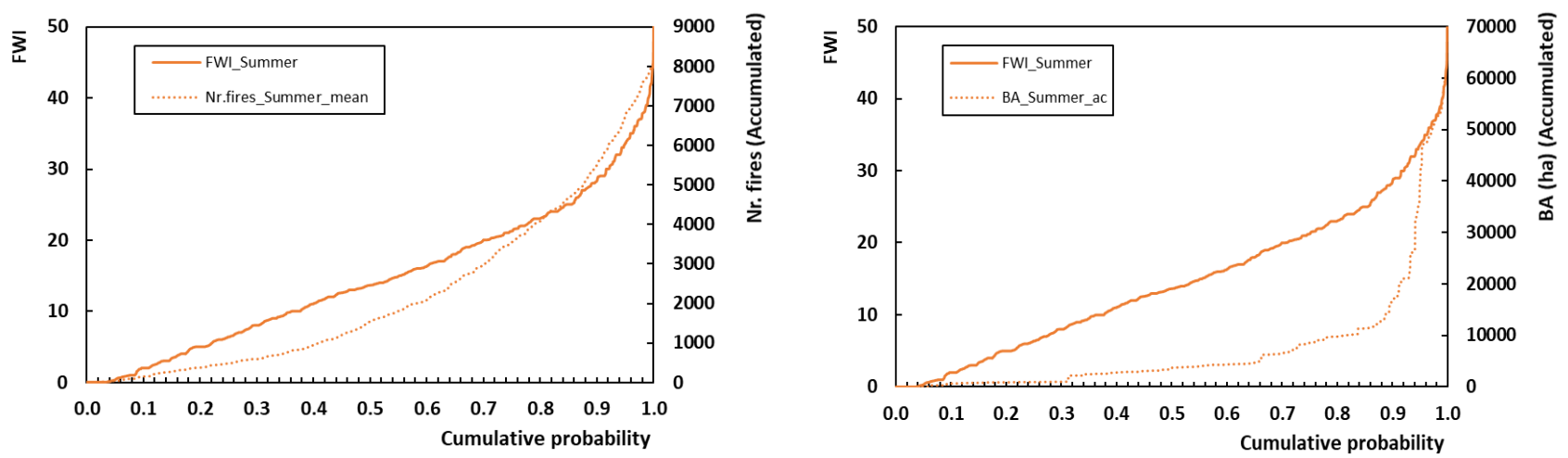

Figure 6 - Plotting FWI distribution in function of the probability - Graphic example for PT111 NUTS3 in Summer. Left-number of accumulated fires. Right-accumulated burned area

These graphics show that the probability of having larger number of fires and burned area increases as FWI increases. 


\subsubsection{Grouping by probability classes and calculating statistics}

From the analysis of the previous graphics (Figure ) we infer the need to categorize the probability into classes. Grouping it into classes is equivalent to splitting the results by percentiles. The breaks used to split classes were $0.1,0.2,0.3,0.4,0.5,0.6,0.7,0.8,0.9,0.95,0.97$. For each class the following parameters were calculated, although the proposed calibration only needs the maximum FWI value of each class:

- Maximum FWI value, limiting the class

- $\quad$ Average FWI value;
- Average number of fires

- Average burned area

Table shows an example of these calculations for PT111 NUTS3 Region, in the Summer period.

Table 5 - Example of results for PT111 NUTS3 region

\begin{tabular}{|c|c|c|c|c|}
\hline \multirow{2}{*}{$\begin{array}{c}\text { Probability } \\
\text { class }\end{array}$} & $\begin{array}{c}\text { Maximum } \\
\text { FWI limit of } \\
\text { the class) }\end{array}$ & FWI & NbF & BA \\
\cline { 3 - 5 } & 2.0 & 0.6 & 1.2 & 5.3 \\
\hline 0.10 & 5.0 & 3.4 & 1.8 & 1.8 \\
\hline 0.20 & 8.0 & 6.4 & 1.7 & 0.8 \\
\hline 0.30 & 11.0 & 9.5 & 2.8 & 14.6 \\
\hline 0.40 & 13.7 & 12.5 & 4.9 & 7.4 \\
\hline 0.50 & 16.3 & 14.9 & 4.4 & 5.0 \\
\hline 0.60 & 20.0 & 18.1 & 7.2 & 18.4 \\
\hline 0.70 & 23.1 & 21.4 & 8.9 & 25.5 \\
\hline 0.80 & 28.4 & 25.4 & 11.6 & 55.4 \\
\hline 0.90 & 33.6 & 30.8 & 20.0 & 366.9 \\
\hline 0.95 & 36.1 & 34.9 & 17.3 & 381.8 \\
\hline 0.97 & 51.2 & 39.4 & 23.7 & 295.0 \\
\hline 1.00 & & & & \\
\hline
\end{tabular}

\subsubsection{Defining risk classes}

The fire risk classes definition, the main goal of this work, was performed by dividing FWI values in groups, according to its historical probability of occurrence. After the individual analysis of a series of random NUTS3 results, calculated in the previous step (2.2.8), it was decided to use, for the Summer period five classes, and for the Winter three classes, with the probability grouped as identified in Table

Table 6 - Proposed "Risk levels" and respective classes in (a) Summer and (b) Winter

\begin{tabular}{|c|c|c|c|c|}
\hline \multirow{2}{*}{ Risk Level } & \multicolumn{2}{|c}{ a. Summer } & \multicolumn{2}{c|}{ b. Winter } \\
\cline { 2 - 5 } & Risk class & $\begin{array}{c}\text { Historical } \\
\text { probability }\end{array}$ & Risk class & $\begin{array}{c}\text { Historical } \\
\text { probability }\end{array}$ \\
\hline $\mathbf{1}$ & Very Low & $\mathrm{P}<0.30$ & Low & $\mathrm{P}<0.50$ \\
\hline $\mathbf{2}$ & Low & $0.30 \leq \mathrm{P}<0.60$ & Moderate & $0.50 \leq \mathrm{P}<0.90$ \\
\hline $\mathbf{3}$ & Moderate & $0.60 \leq \mathrm{P}<0.90$ & High & $\mathrm{P} \geq 0.90$ \\
\hline $\mathbf{4}$ & High & $0.90 \leq \mathrm{P}<0.97$ & - & - \\
\hline $\mathbf{5}$ & Very High & $\mathrm{P} \geq 0.97$ & - & - \\
\hline
\end{tabular}

\subsubsection{Merging final calibration tables}

The result of the described process consists of two tables for each NUTS3 region, one for Summer and one for Winter. 
The final step of the methodology is the merging of all individual tables for each season: one calibration table for European NUTS3 regions for Summer and another for Winter. To accomplish this, the "Probability" lines need to be transposed into columns, maintaining the FWI Maximum values filling the line for the respective NUTS3 region.

A simple merge of all the NUTS3 individual results produces the final Calibration Tables, like in the example given below (Table and Table ).

\section{Results}

The entire process, performed for all NUTS3 regions in the defined AoI, resulted in two calibration tables, one for Summer and other for Winter, as defined before.

\subsection{Calibration tables}

The calibration table for Summer has 6 columns:
i. COUNTRY
iv. Break_Prob_60
ii. NUTS_ID
v. Break_Prob_90
iii. Break_Prob_30
vi. Break_Prob_97

The first two are self-explanatory, as they represent the country and the NUTS3 identification code. The last 4 represent the breaks used to define the five risk classes, as explained earlier (Table ).

The calibration table for Winter has 4 columns:
i. COUNTRY
iii. Break_Prob_50
ii. NUTS_ID
iv. Break_Prob_90

Again, the first two are self-explanatory and the last 2 represent the breaks used to define the three risk classes.

In Table and Table the calibration table with the threshold values just for 22 from 769 NUTS3, for Summer and for Winter, respectively is presented.

Table 7 - Calibration table for Summer (22 from 769 NUTS3)

\begin{tabular}{|c|c|c|c|c|c|c|}
\hline & Country & NUTS_ID & Break_P_30 & Break_P_60 & Break_P_90 & Break_P_97 \\
\hline 1 & BG & BG312 & 7.8 & 22 & 39.5 & 51 \\
\hline 2 & CH & CH023 & 0.9 & 5.6 & 13.9 & 19.6 \\
\hline 3 & CY & CY000 & 25.5 & 32 & 44.1 & 50.5 \\
\hline 4 & CZ & CZ041 & 2.8 & 9.6 & 20.6 & 27.6 \\
\hline 5 & DE & DE122 & 4.7 & 13 & 24.7 & 30.7 \\
\hline 6 & EE & EE001 & 1 & 4.3 & 11 & 19 \\
\hline 7 & EL & EL111 & 19.8 & 33.8 & 51.4 & 58.2 \\
\hline 8 & ES & ES411 & 28 & 39.2 & 52.8 & 62.5 \\
\hline 9 & FI & FI195 & 0.7 & 4.2 & 13.7 & 25 \\
\hline 10 & FR & FR213 & 6 & 15 & 29 & 38.7 \\
\hline 11 & HR & HR035 & 15.7 & 29.4 & 47.5 & 56 \\
\hline 12 & HU & HU222 & 8.4 & 19.1 & 35.3 & 45.6 \\
\hline 13 & IT & ITC34 & 0.6 & 6.4 & 17.4 & 22.9 \\
\hline 14 & LT & LT001 & 2.5 & 8.8 & 20.7 & 29.5 \\
\hline 15 & LV & LV003 & 2.1 & 7.4 & 19.4 & 29.4 \\
\hline 16 & PL & PL114 & 5.7 & 15 & 28 & 40.3 \\
\hline 17 & PT & PT114 & 6 & 13.8 & 24.1 & 32.5 \\
\hline 18 & RO & RO116 & 5.9 & 17 & 31.7 & 38.8 \\
\hline 19 & SE & SE122 & 1.6 & 8 & 21 & 29.2 \\
\hline 20 & SI & SI012 & 5 & 14.9 & 29 & 40 \\
\hline 21 & SK & SK022 & 6.1 & 16.3 & 29 & 37.5 \\
\hline 22 & TR & TR411 & 28.4 & 45.1 & 60.8 & 68.6 \\
\hline
\end{tabular}


Table 8 - Calibration table for Winter (22 from 769 NUTS3)

\begin{tabular}{|c|c|c|c|c|}
\hline & Country & NUTS_ID & Break_P_50 & Break_P_90 \\
\hline 1 & BG & BG312 & 1.0 & 16.3 \\
\hline 2 & CH & CH023 & 0.4 & 6.0 \\
\hline 3 & CY & CY000 & 12.4 & 30.2 \\
\hline 4 & CZ & CZ041 & 0.4 & 8.6 \\
\hline 5 & DE & DE122 & 0.7 & 9.1 \\
\hline 6 & EE & EE001 & 0.5 & 4.3 \\
\hline 7 & EL & EL111 & 2.2 & 15.2 \\
\hline 8 & ES & ES411 & 5.9 & 23.3 \\
\hline 9 & FI & FI195 & 0.2 & 1.0 \\
\hline 10 & FR & FR213 & 0.8 & 12 \\
\hline 11 & HR & HR035 & 3.3 & 18 \\
\hline 12 & HU & HU222 & 2.3 & 18.3 \\
\hline 13 & TT & ITC34 & 0.3 & 4.2 \\
\hline 14 & LT & LT001 & 0.3 & 8.0 \\
\hline 15 & LV & LV003 & 0.4 & 5.1 \\
\hline 16 & PL & PL114 & 0.8 & 12.6 \\
\hline 17 & PT & PT114 & 1.6 & 10.1 \\
\hline 18 & RO & RO116 & 0.9 & 15.9 \\
\hline 19 & SE & SE122 & 0.4 & 7.0 \\
\hline 20 & SI & SI012 & 1.0 & 13.3 \\
\hline 21 & SK & SK022 & 0.7 & 13.1 \\
\hline 22 & TR & TR411 & 4.6 & 23.5 \\
\hline
\end{tabular}

Two scripts in Python language were written to facilitate the calibration process and allow integration with other tools. The scripts classify FWI values into calibrated fire risk classes, according to the proposed methodology.

\section{Final considerations}

One of the main constrains inherent to the proposed calibration was the lack of consistent data. Meteorological data was available for the entire EU area, but fire records were not. The absence of these records has a strong influence in the significance of the calibration values. The longer the data series used, the higher the confidence in the results. Assuming this, we advise that the calibration is recalculated whenever larger series of data are compiled.

In our opinion, at an European level it is worthy using NUTS 3 as the minimum spatial unit, as it highlights differences between and within larger regions.

The full process of calibration was achieved using ArcGIS models that allow "scripting" for users who are not familiar with programing in python language. Models allowed the splitting of the somehow complex set of operations and the easy iteration of multiple tables at once. Although the set of models built allows for the replication of the calibration process, they use specific ArcGIS tools and commands, but a ready-to-use python script to be used by other platforms was not done yet.

This calibration is based on the assumption of the existence of a good correlation between fire occurrence expressed by the number of daily fires and burned area. In a similar work to JRC, we calculated the correlation coefficient between FWI and number of fires and burned area, separately for Summer and Winter period in order to confirm our assumption. Then we checked if the calibration that was produced worked well to predict days with very large burned area both in Summer and Winter periods. We found that there is a good correlation in areas with important fire activity while in the others the correlation may not be so good. We also found that in some regions the FWI may not be sufficient to predict days with large fire activity and possibly other indices should be used to 
complement it and in areas in which winter fires are relatively important it may be necessary to introduce five fire danger classes.

\section{Acknowledgments}

The authors acknowledge JRC for the support provided by the Contract JRC-FWI (JRC/G02/E/rc/Ares (2016)). The partial support provided by projects FIREXTR (PTDC/ATPGEO/0462/2014), FIREWHIRL (PTDC/EMS-ENE/2530/2014) is also gratefully acknowledged.

\section{References}

European Commission. (2018). Eurostat. Cbtained from https://ec.europa.eu/eurostat/web/nuts/background

Forestry Canada Fire Danger Group. (1992). Development and structure of the Canadian Forest Fire. (p. 63). Ottawa: Forestry Canada.

Reis, R. M. (1998). Scales for the assessment of forest fire danger. In Proc. of III International Conf. on Forest Fire Research/14th Conf. on Fire and Forest Meteorology, I, pp. 1235-1247. Luso.

Rocha, C. F. (2014). Validação do Índice de Risco de Incêndio Florestal - ICRIF. Master thesis, University of Coimbra.

Stocks, B.J., Lawson, B.D., Alexander, M.E., Van Wagner, C.E., McAlpine, R.S., Lynham, T.J., Dube, D.E., 1989. The Canadian forest fire danger rating system: an overview. The Forestry Chronicle $65,258-265$

Van Wagner, C. (1987). Development and structure of the Canadian Forest Fire Weather Index System. Otawa: Canadian Forestry Service, Forestry Technical Report 35.

Viegas, D. X., Bovio, G., Ferreira, A., Nosenzo, A., \& Sol, B. (1999). Comparative study of various methods of fire danger evaluation in Southern Europe. International Journal of Wildland Fire, 9(4): 235-246.

Viegas, D. X., Reis, R. M., Cruz, M. G., \& Viegas, M. T. (2004). Calibração do Sistema Canadiano de Perigo de Incêndio para Aplicação em Portugal. 77-94. EFN, Lisboa: Silva Lusitana.

Viegas, D. X., Rossa, C., \& Ribeiro, L. M. (2011). Incêndios Florestais. Lisboa: Verlag Dashofer.

Viegas, D. X., Sol, B., Bovio, G., Nosenzo, A., \& Ferreira, A. D. (1994). Comparative study of various methods of fire danger evaluation in Southern Europe. In Proceedings of the II International Conference on Forest Fire Research, (pp. 571-590). Coimbra.

Xanthopoulos, G., Roussos, A., Giannakopoulos, C., Karali, A., \& Hatzaki, M. (2014). Investigation of the weather conditions leading to large forest fires in the area around Athens, Greece. In D. X. Viegas, \& ADAI-CEIF (Ed.), Advances in Forest Fire Research (pp. 1207-1212). Coimbra: Imprensa da Universidade de Coimbra. doi:http://dx.doi.org/10.14195/978-989-26-0884-6 